\title{
Planejamento metropolitano e grandes projetos urbanos: concepção e descaminhos da política de novas centralidades na RMBH
}

\author{
Metropolitan planning and large urban projects: \\ conception and mismatches of the new centralities \\ policy in the Metropolitan Region of Belo Horizonte
}

João B. M. Tonucci Filho [I] Daniel Medeiros de Freitas [II]

\section{Resumo}

Nas últimas décadas, dois processos caracterizaram a política e a dinâmica urbana da Região Metropolitana de Belo Horizonte (RMBH): a retomada do planejamento metropolitano e a maior intensidade de grandes projetos urbanos (GPUs). Este trabalho investiga criticamente as relações entre um conjunto de GPUs, executados e/ou idealizados entre 2000 e 2018, e o planejamento em construção, com ênfase nos projetos para centralidades nos Vetores Norte e Sul da RMBH. Para tal, busca-se articular a análise do campo de poder dos GPUs com a análise do processo de planejamento. As conclusões evidenciam aproximações, contradições e descaminhos entre o planejamento, o Governo do Estado e o capital imobiliário, principalmente quanto à política de novas centralidades.

Palavras-chave: planejamento metropolitano; grandes projetos urbanos; centralidades metropolitanas; Região Metropolitana de Belo Horizonte.

\begin{abstract}
In recent decades, two processes have characterized the urban policy and urban dynamics of the Metropolitan Region of Belo Horizonte (MRBH): the resumption of metropolitan planning and the greater intensity of large urban projects (LUPS). This paper critically investigates the relationships between a set of LUPS, executed and/or designed between 2000 and 2018, and the planning under construction, with emphasis on projects for centralities in the north and south vectors of MRBH. To this end, it articulates the analysis of the LUPs' field of power with the analysis of the planning process. The conclusions highlight approximations, contradictions and mismatches between planning, the State Government and real estate capital, especially regarding the new centralities policy.
\end{abstract}

Keywords: metropolitan planning; large urban projects; metropolitan centralities; Metropolitan Region of Belo Horizonte. 


\section{Introdução ${ }^{1}$}

Nas décadas de 2000 e 2010, dois processos caracterizaram a política e a dinâmica urbana da Região Metropolitana de Belo Horizonte (RMBH): a retomada do planejamento metropolitano, por meio da elaboração do Plano Diretor de Desenvolvimento Integrado (PDDI-RMBH) e do Macrozoneamento Metropolitano (MZ-RMBH); e a maior intensidade de grandes projetos urbanos (GPUs), incluindo a retomada dos investimentos em estrutura viária, grandes projetos imobiliários, operações urbanas e um conjunto de empreendimentos relacionados ao planejamento estratégico no Vetor Norte e no Vetor Sul. Percebe-se, no entanto, um deslocamento entre as propostas do planejamento metropolitano - dentre as quais se destaca a política metropolitana de criação e fortalecimento de novas centralidades, principal elemento da proposta de reestruturação territorial do PDDI - e a lista de GPUs realizados e previstos, resultando em conflitos entre interesses regionais e locais e entre os planos de longo prazo e projetos mais pontuais.

0 objetivo deste trabalho é discutir criticamente as relações entre o planejamento metropolitano e os GPUs, ${ }^{2}$ com ênfase nos projetos para novas centralidades na RMBH. Mais especificamente, busca-se investigar o modo como um conjunto de projetos executados e/ ou idealizados entre 2000 e 2018, especificamente no Vetor Norte e Vetor Sul da RMBH, atravessou, alterou ou se apropriou desse processo de planejamento em construção. Algumas questões orientam a investigação, ainda preliminar: como os GPUs foram considerados pelo PDDI, pelo macrozoneamento e pelos demais produtos do planejamento territorial da $\mathrm{RMBH}$, incluindo o Plano de Mobilidade e os processos em curso de revisão dos planos diretores municipais? Quem define a agenda de GPUs e como ocorre a permeabilidade da política urbana a ela? Como essa lista de GPUs dada a priori dialoga com os mecanismos de participação previstos no planejamento? E com a especificidade dos locais? Qual a distribuição metropolitana do ônus e bônus desses projetos? Até que ponto promovem articulações que se sobrepõem ou confrontam a agenda urbana? Qual o real papel do planejamento na viabilização e articulação desses projetos?

Para avançar nessas questões, os GPUs, assim como os projetos públicos e/ou privados para as novas centralidades, foram analisados de modo relacional e com ênfase no histórico de articulações e inflexões na estrutura do campo de poder que os estrutura, utilizando dados de pesquisa iniciada em 2014 sobre o tema (Freitas, 2017). Já os produtos e os processos do planejamento metropolitano foram estudados a partir de seus principais documentos, do registro do processo participativo e do acompanhamento, pelos autores, dos debates e conflitos surgidos no âmbito das instâncias executivas (Agência RMBH) e deliberativas (Conselho Metropolitano) da gestão metropolitana. A leitura desse material foi focada na problemática da permeabilidade entre interesses privados e o processo institucional de planejamento, que podem colocar em xeque os avanços conceituais e políticos já alcançados na esfera metropolitana. De modo mais geral, busca-se contribuir para, passados mais de dez anos do novo arranjo de gestão e planejamento metropolitanos, avaliar criticamente seus avanços, limites e desafios.

0 artigo está estruturado em três partes. Na primeira, apresentamos brevemente a trajetória recente de planejamento 
metropolitano na RMBH, destacando e detaIhando como a proposta de reestruturação territorial metropolitana - principalmente a política de novas centralidades metropolitanas - comparece no PDDI e no macrozoneamento. Em seguida, os principais GPUs concebidos e/ou realizados entre 2000 e 2018 são apresentados, e o trabalho analisa mais detaIhadamente as relações (políticas, econômicas e territoriais) entre alguns grandes projetos, o planejamento metropolitano e a política das novas centralidades norte e sul. Por fim, levantamos algumas conclusões preliminares acerca da aproximação e/ou contradição entre o planejamento metropolitano, o Governo do Estado e o capital (principalmente imobiliário) quanto à política de criação de novas centralidades metropolitanas, assim como acerca dos desdobramentos socioespaciais das decisões públicas e privadas relacionadas à reestruturação territorial da $\mathrm{RMBH}$.

\section{Planejamento metropolitano e a política de novas centralidades na RMBH}

A retomada do planejamento metropolitano na $\mathrm{RMBH}^{3}$ ocorre em 2007 por meio da realização da I Conferência Metropolitana, da instalação do Conselho Deliberativo e da Assembleia Metropolitana, da regulamentação do Fundo de Desenvolvimento Metropolitano e da criação da Subsecretaria de Desenvolvimento Metropolitano. Em 2009, ocorre a criação da Agência de Desenvolvimento Metropolitano (Agência RMBH) e tem início a elaboração do Plano Diretor de Desenvolvimento Integrado (PDDI-RMBH), concluído em 2011. ${ }^{4}$ Orientaram a elaboração do PDDI-RMBH a construção dos sentidos de cidadania e solidariedade metropolitanas, a ampliação da inclusão social e econômica, o fortalecimento da justiça social e ambiental, a redução das desigualdades e da pobreza, a valorização das diversidades socioambientais, o novo papel nacional e regional da RMBH, o "Novo Pacto" metropolitano e a inversão de prioridades metropolitanas.

Por se tratar de um Plano elaborado no contexto da universidade, enfatizou-se uma orientação crítica, voltada para a rearticulação entre as dimensões analíticas, parciais e operativas com o sentido da totalidade. Por fim, a equipe do Plano assumiu como seu objetivo central dar início à construção de um Sistema de Planejamento Metropolitano permanente, incluindo as universidades e os demais agentes e instâncias atuantes na produção e disseminação de conhecimento sobre a RMBH, articulando-se ao Sistema de Gestão Metropolitana instituído (Tonucci Filho e Monte-Mór, 2013).

Neste trabalho, enfatizamos o conteúdo de uma das propostas-chave do Plano, a Proposta de Reestruturação Territorial Metropolitana, seus pressupostos e objetivos, assim como algumas limitações e condicionantes de implementação. Essa proposta baseou-se nas seguintes macrodiretrizes estabelecidas pela Assembleia Metropolitana:

Dentre as macrodiretrizes de caráter transversal, a reorganização territorial é considerada estratégica para a definição do caráter do PDDI para a RMBH. Pressupõe-se o sistema viário e de transporte como componente indutor da ocupação e do uso do solo, com uma mobilidade metropolitana organizada em rede, que dissemine ao máximo no território o acesso às oportunidades de desenvolvimento. Propõe-se 
o estímulo à criação de novas centralidades microrregionais e a habitação como uso estruturante da metrópole, dentre outras intervenções no espaço metropolitano que possibilitem a redução das desigualdades socioespaciais, princípio primeiro de gestão metropolitana segundo a Lei 88/2006. (Sedru, 2009, p. 4)

Ademais, a proposta adotou 2023 como horizonte referencial de médio prazo e 2050 como de longo prazo, não se excluindo, todavia, a possibilidade de ela sofrer revisões ao longo do processo de implementação do PDDI. Esse olhar estrutural de longo prazo ultrapassaria a busca de soluções operacionais para os problemas imediatos da $\mathrm{RMBH}$, procurando antes ser um norte intencional para guiar a ação dos entes públicos e privados, antecipando-se às demandas e aos desafios futuros da RMBH no sentido da construção de uma região metropolitana mais dinâmica, igualitária e sustentável.

A proposta territorial alicerçou-se sobre duas políticas estruturantes - a Política Metropolitana Integrada de Centralidades em Rede e a Política Metropolitana Integrada de Regulação do Uso e da Ocupação do Solo (UFMG, 2011). A primeira, constituída por diretrizes concretas e espacializadas, é norteadora de uma localização seletiva e qualificada dos investimentos públicos e privados no território metropolitano, enquanto a segunda busca a construção de marcos regulatórios viabilizadores da proposta de reestruturação territorial e das demais propostas contidas no Plano, atuando principalmente sobre os instrumentos normativos e mecanismos de gestão (MagaIhães et al., 2012).
A leitura dos processos de produção e apropriação do espaço que orientou a formulação dessas políticas apontou um conjunto de tendências para a dinâmica territorial metropolitana na década anterior: o recrudescimento das desigualdades socioespaciais e do modelo centro-periferia de estruturação territorial; a crescente perda de mobilidade urbana; a grande vacância domiciliar e fundiária disseminada por toda a RMBH; as crescentes dispersão e fragmentação do tecido urbano; o agravamento dos conflitos entre as diversas modalidades de uso do solo; o crescente comprometimento dos recursos ambientais de alcance metropolitano; a manutenção da excessiva concentração da oferta de serviços e de empregos no núcleo central de Belo Horizonte; e a tendência de manutenção dos investimentos privados nos municípios já economicamente dinâmicos (UFMG, 2011).

Para reverter e contrapor-se a esses processos, a proposta territorial visou a uma descentralização concentrada e seletiva das atividades e dos investimentos urbanos, em contraposição à tendência pautada na concentração excessiva em um único centro e na expansão fragmentada e descontínua da mancha urbana (ibid.). Segundo Tonucci Filho (2012), essa estratégia visou à reversão das extremas desigualdades socioespaciais da RMBH decorrentes do modelo centro-periferia e do padrão radioconcêntrico de estruturação territorial, através da proposição de uma rede de centralidades multiescalar e de uma rede de mobilidade multimodal, assim como da extensão da infraestrutura e dos serviços urbanos básicos a toda RMBH. A diretriz de combate à dispersão urbana exprime a incorporação da questão ambiental na proposta territorial, a partir 
das estratégias de constituição de um tecido metropolitano mais compacto e coeso, do aumento das densidades junto às centralidades e aos pontos de maior acessibilidade, e do combate às vacâncias, protegendo as áreas rurais e ambientalmente relevantes.

Duas categorias distintas de uso e ocupação do solo e de organização espacial das atividades econômicas foram definidas na proposta de reestruturação territorial: os eixos de estruturação metropolitana e as centralidades em rede. Os eixos configurariam áreas em torno das vias estruturantes de ligação da $\mathrm{RMBH}$ com outras regiões do estado e do País, onde se localizariam grandes equipamentos de infraestrutura e serviços, áreas industriais, usos de maior porte ligados ao setor terciário e formas de ocupação mais espraiada. Os eixos teriam a função de direcionar o crescimento metropolitano, devendo incluir centralidades que teriam a função de organizar espacialmente cada eixo (Magalhães et al., 2012). As centralidades seriam áreas urbanas com alta densidade econômica, forte heterogeneidade de usos (concentração diversificada de empregos, comércio e serviços públicos e privados), grande complexidade funcional e adensamento residencial e que deteriam acessibilidade privilegiada às redes de transporte público coletivo (UFMG, 2011). Além dessas dimensões econômicas e funcionais, as centralidades foram entendidas enquanto espaços que possibilitariam a intensificação da "vida urbana", através da presença de equipamentos culturais e espaços públicos qualificados para a fruição do pedestre, possibilitando, assim, grande diversidade de manifestações socioculturais e políticas centrais para o fortalecimento das múltiplas identidades metropolitanas. A rede de centralidades proposta busca configurar uma nova hierarquia urbana na RMBH. A Figura 1 apresenta a proposta da hierarquia de centralidades (detalhada em seguida) e a distribuição territorial dos eixos de estruturação metropolitana para a RMBH.

A rede de centralidades proposta abrange as seguintes escalas: a Metrópole (centro metropolitano principal, consolidado no núcleo central de Belo Horizonte, e expandindo-se na região Centro-Sul e ao longo dos eixos viários na direção do município de Nova Lima); Centros metropolitanos (propostas das novas centralidades Oeste em Betim, Norte em Vespasiano e Sul em Nova Lima); Subcentros metropolitanos (subcentralidades já existentes e tipicamente populares, como Venda Nova em Belo Horizonte, São Benedito em Santa Luzia, Barreiro em Belo Horizonte, Eldorado em Contagem, centro de Sabará, Jardim Canadá em Nova Lima, e um novo centro Leste, na localidade de Ravena, município de Sabará); Centros microrregionais (áreas intermediárias voltadas à polarização de um conjunto de bairros e/ou de municípios vizinhos menores); e Centros locais (centralidades de menor nível, correspondentes a muitas das sedes dos municípios menos populosos da RMBH que servem como centros de apoio ao meio rural) (ibid.).

Neste trabalho, interessam-nos principalmente as propostas dos novos centros metropolitanos, que teriam a função de organizar territórios extensos da RMBH. Segundo o Plano (ibid.), os centros metropolitanos deveriam se estruturar em torno de quatro pilares: uso residencial em grande quantidade e densidade, incluindo a habitação de interesse social; ligação com as economias industriais em seu entorno; forte aspecto cultural e ambiental, com equipamentos diversos e atividades diretamente relacionadas aos complexos 
Figura 1 - Mapa centralidade e eixos de estruturação metropolitana

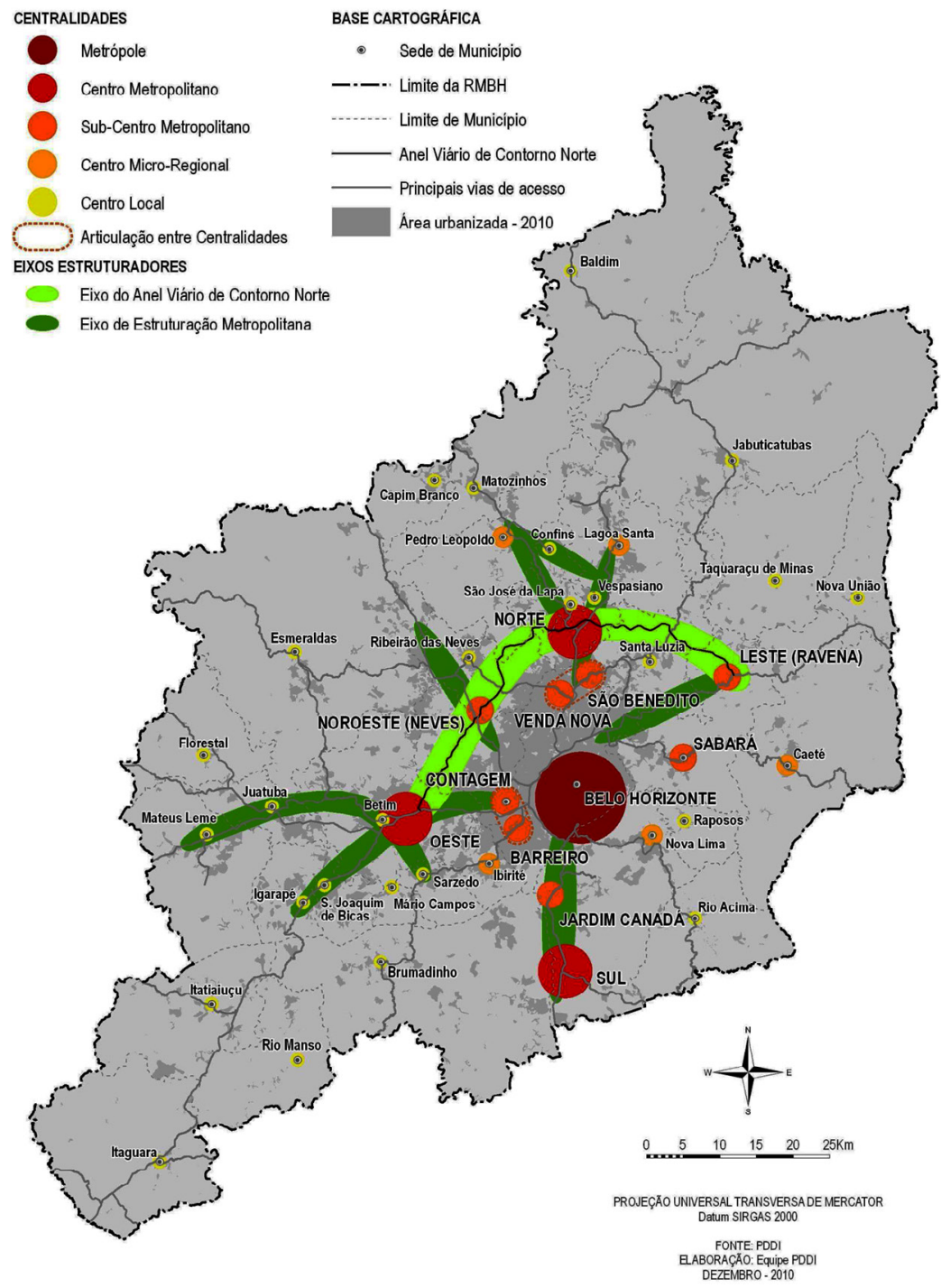

Fonte: UFMG (2011). 
ambientais e culturais regionais; e interligação em rede com outras centralidades através de estações da rede de mobilidade.

Para o Centro Metropolitano Norte, o PDDI, considerando os inúmeros empreendimentos e intervenções públicas previstas para o Vetor Norte da RMBH, recomendou a criação de um centro de nível metropolitano capaz de polarizar esse território, que hoje abriga grande contingente de população de baixa renda. A localização exata da nova centralidade a ser criada seria definida em estudos complementares específicos, mas o Plano indicou a região ao norte do futuro Anel Viário de Contorno Norte, entre as vias MG-424 e MG-10, no município de Vespasiano. O plano recomendou, ainda, promover a integração desse centro com as demais centralidades, através de sua integração à rede de transporte de massa proposta, e com os demais centros urbanos da sua proximidade (Vespasiano, São José da Lapa, Pedro Leopoldo, Lagoa Santa e Confins). Esse novo centro deveria, também, ser dotado de intensa vida urbana e identidade cultural associada ao rico patrimônio arqueológico, histórico e ambiental do Complexo Ambiental e Cultural Carste presente em grande parte do Vetor Norte.

O Centro Metropolitano Oeste assentar-se-ia sobre o município de Betim, buscando aumentar a polarização desse município sobre outras cidades do eixo oeste. Essa centralidade justifica-se pela tendência de crescimento do setor produtivo em Betim - notadamente a expansão da Fiat - com repercussões e transbordamentos para outros municípios vizinhos, como Juatuba e São Joaquim de Bicas; assim como pelo crescimento do setor de serviços, principalmente em Contagem. Uma centralidade desse nível em Betim, que conjugasse a oferta diversificada de serviços e de empregos, contribuiria para reduzir a pressão de viagens ao núcleo central de Belo Horizonte, além de propiciar menores deslocamentos e maior acessibilidade à população da região. A localização exata dessa nova centralidade deve ser objeto de estudos específicos, mas é importante que ela deva estar articulada ao futuro anel viário de Contorno Norte, à BR-381 e BR-262, à proposta de expansão do metrô até Betim e à construção de um novo ramal ferroviário oeste entre Betim e Vespasiano. Essas novas propostas de mobilidade confeririam uma acessibilidade privilegiada a Betim dentro do contexto de toda a RMBH o que é condição essencial para o desenvolvimento de uma nova centralidade desse porte.

Outro ponto de destaque em relação às centralidades norte e oeste é que a construção do anel viário de Contorno Norte (AVCN), ou Rodoanel - projeto previsto há anos para a $\mathrm{RMBH}$ - promoveria uma ligação direta entre esses dois vetores de expansão metropolitana, o que é um fato muito significativo para a estrutura metropolitana e sua relação com a esfera produtiva, pois promoveria a integração entre duas grandes regiões da RMBH de forma mais independente do núcleo metropolitano. Segundo Magalhães et al. (2012), as deseconomias de aglomeração hoje observadas no eixo Oeste poderiam ser suavizadas a partir de sua integração com essa área do Vetor Norte, onde esses fatores ainda não se encontram tão presentes, promovendo, ainda, uma ligação da região mais industrializada com o aeroporto internacional Tancredo Neves (AITN). O PDDI reconheceu o potencial transformador do futuro AVCN sobre o uso do solo no seu entorno e o seu poder de atração sobre a expansão urbana, conforme será 
reforçado pelo macrozoneamento, discutido em seguida. Diante da inevitabilidade dessa incorporação futura do Rodoanel à aglomeração urbana e da necessidade de se pensar um projeto urbanístico de adensamento controlado no seu entorno, resguardadas as áreas de proteção ambiental, a proposta identificou-o, no mapa, como um eixo de estruturação metropolitana diferenciado.

Por fim, e ao contrário das centralidades Norte e Oeste, e em função da natureza mais espraiada do processo de urbanização que vem ocorrendo no Vetor Sul, o PDDI propôs duas centralidades como parte do Centro Metropolitano Sul, em áreas nas quais já vêm ocorrendo um adensamento incipiente do setor terciário e de equipamentos. O Plano (UFMG, 2011) indicou as regiões do Jardim Canadá e do Alphaville (em localidades exatas a serem definidas em estudos complementares) como áreas privilegiadas para a configuração de novas centralidades. Esses novos centros, densos e diversificados, devem ter capacidade de polarizar e organizar o território espraiado e de baixa densidade do eixo Sul. Devem também estar associados ao Complexo Ambiental e Cultural do Quadrilátero Ferrífero, detentor de vasto patrimônio histórico ligado ao ciclo do ouro e a um rico patrimônio geoambiental e paisagístico. Como a proliferação dispersa de novas atividades ao longo do Vetor Sul já tem trazido impactos ambientais significativos, e considerando que essas centralidades estariam inseridas na Área de Proteção Ambiental Sul da RMBH (APA-Sul) e próximas de outras unidades de conservação, como o Parque Estadual da Serra do Rola Moça, o Plano adverte que a proposta de novos centros deverá dar um tratamento diferenciado ao adensamento da região, devido à questão ambiental.
Ao longo de 2011, após aprovação do Plano pelo Conselho Metropolitano, a Agência RMBH elaborou uma agenda de trabalho voltada à sua absorção pelo Estado, selecionando algumas propostas para integrarem as revisões do Plano Mineiro de Desenvolvimento Integrado (PMDI) e do Plano Plurianual de Ação Governamental (PPAG). Àquela época, o Governo do Estado considerou como prioritários os seguintes temas: mobilidade metropolitana, sistema ferroviário, novas centralidades e saneamento e resíduos sólidos. Elencadas como um tema prioritário, as novas centralidades passaram a ser discutidas com potenciais parceiros privados (proprietários e/ou investidores), do que resultaram algumas propostas concretas e mesmo estudos urbanísticos, como se verá mais adiante. Posteriormente, a rede de centralidades foi incorporada no Macrozoneamento Metropolitano, que se tornou um dos projetos prioritários da Agência de Desenvolvimento da RMBH. ${ }^{5}$

O Macrozoneamento Metropolitano (MZ-RMBH) constitui um dos programas previstos na Política Metropolitana Integrada de Regulação do Uso e da Ocupação do Solo do PDDI. A elaboração do Macrozoneamento, contratado pela Agência RMBH à UFMG, transcorreu durante os anos de 2013 e 2014 e teve seu produto final consolidado em 2015. Sua elaboração contou com a participação significativa de representantes dos municípios e da sociedade civil organizada em movimentos sociais, associações empresariais e populares. Respeitando o compartilhamento de responsabilidades com os municípios, ele foi, então, submetido à avaliação dos prefeitos e técnicos municipais, passando por uma nova rodada de ajustes. Posteriormente, foi incorporado junto ao PDDI o Projeto de Lei 
Complementar 74, enviado à Assembleia Legislativa em 2017. O PLC 74/2017, que "institui o Plano Diretor de Desenvolvimento Integrado da RMBH", foi elaborado em cumprimento ao Estatuto da Metrópole (lei federal $n$. 13.089/2015). Por falta de condições políticas, o projeto não chegou a ser votado e se encontra arquivado atualmente.

Deve-se ter sempre em vista que, enquanto não for aprovado segundo os requisitos do Estatuto da Cidade, o PDDI-RMBH tem natureza apenas indicativa e não compulsória, ainda que aprovado nas instâncias representativas do sistema de gestão metropolitano - Conselho e Assembleia Metropolitanos. Assim, ele tem sido entendido mais como um marco referencial e orientador para ações estaduais e municipais na RMBH, cuja legitimidade sociopolítica repousa em tênue acordo firmado entre membros da gestão colegiada da RMBH - estado, municípios e sociedade civil (Tonucci Filho, 2012).

O Macrozoneamento Metropolitano contém limites, diretrizes e parâmetros urbanísticos para cada uma das dezenove Zonas de Interesse Metropolitano (ZIMs) identificadas no trabalho. Cada ZIM constitui um território delimitado no qual o interesse metropolitano é preponderante em relação ao interesse local, especialmente no que se refere às chamadas funções públicas de interesse comum. Para tal, define diretrizes e parâmetros gerais que orientam a reestruturação territorial, o desenvolvimento produtivo sustentável, a proteção e desenvolvimento ambiental, a regulação urbanística e os parâmetros gerais das ZIMs (UFMG, 2015).

Tal como explicado em sua metodologia, o MZ-RMBH considerou como parte da estrutura urbana atual as áreas urbanas consolidadas ou parceladas, as centralidades existentes, os grandes usos e equipamentos de grande porte, os grandes projetos, as unidades de conservação e os grandes vazios urbanos [...] as zonas de proteção ambiental e zonas de interesse social existentes a partir dos zoneamentos em vigor nos respectivos municípios. (UFMG, 2015, p.13)

Essa opção é determinante no modo como um conjunto de grandes obras, equipamentos públicos e empreendimentos privados em diferentes estágios de viabilidade são incorporados ao planejamento metropolitano. Nesse sentido, projetos de maior capital político, sobretudo aqueles alinhados ao plano estratégico do Vetor Norte ou a interesses de grandes agentes econômicos, conforme será retomado, são incluídos com maior visibilidade nos cenários considerados pelo planejamento de longo prazo.

Buscando articular esses projetos ao horizonte temporal do planejamento, os grandes projetos de interesse metropolitano, localizados dentro das ZIMs, foram demarcados de dois modos: como Zona de Diversificação e Adensamento (ZDA) nos casos de potencial conformação de nova centralidade; ou como ZDEM de Grandes Equipamentos, quando considerados "objeto de regulamentação específica em função da magnitude dos impactos que potencialmente podem causar na estrutura urbana e meio ambiente" (UFMG, 2015 , p. 30). O principal objetivo é "condicionar o licenciamento ambiental e urbanístico de grandes projetos à previsão de espaços livres de uso público, habitação de interesse social (20\%) e incorporação da Trama Verde e Azul" (ibid., p. 27). 
O zoneamento proposto para as ZIMs Vetor Sul e Vetor Norte, apresentado na Figura 2, possui maior relação com a argumentação desenvolvida neste trabalho. No Vetor Sul, a delimitação do limite da ZIM levou em conta o limite da propriedade do empreendimento CSul, distrito de grande porte que contempla áreas destinadas a habitação e equipamentos de serviços, lazer, educação e trabalho, conforme será retomado adiante. A ZDA adotada busca "agregar áreas às margens da BR-040 com capacidade de adensamento futuro e com potencial de compor a centralidade sul da RMBH", incluindo "áreas de expansão industrial e de serviços ao longo da rodovia, o Condomínio Alphaville e demais condomínios do entorno, a área da CSul e sua possível área de influência" e recomendando que "os projetos de grande impacto deverão destinar uma porcentagem de sua área para uso público e para habitação de interesse social Faixa 1" (ibid., p. 35).

Na ZIM Vetor Norte, a extensa ZDA considerou

os impactos do projeto do Rodoanel e os novos projetos de larga escala, como o condomínio Terras do Fidalgo (antigo Precon Park, incluindo o Fashion City e o condomínio Alphaville em Vespasiano), o projeto do condomínio elaborado pela empresa de consultoria Aecon (incluído como uma das áreas- alvo no plano econômico elaborado pela $\mathrm{CH} 2 \mathrm{M}$ HILL). (Ibid., p. 36)

Figura 2 - Zoneamentos internos das ZIMs Sul, à esquerda, e Norte, à direita
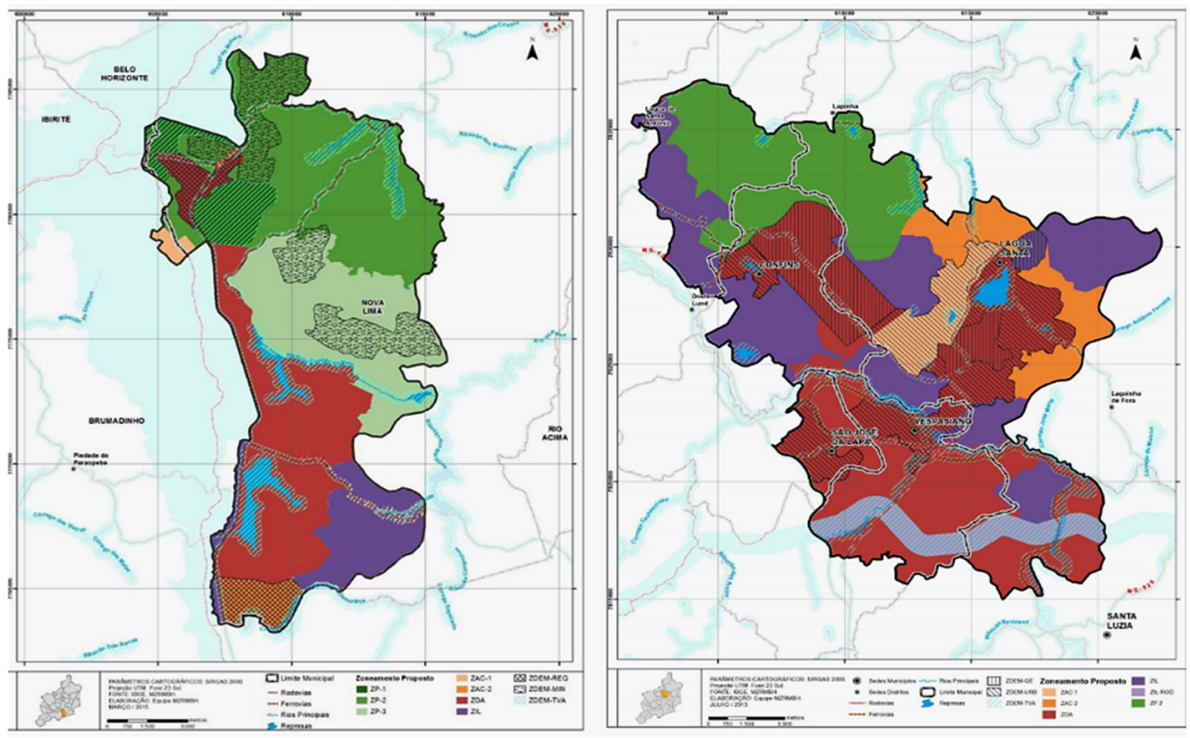

Fonte: UFMG (2015). 
A ZDA incorpora, ainda, os zoneamentos municipais de Vespasiano e Santa Luzia que destacam essa região para a implantação de grandes empreendimentos e equipamentos. Além da ZDA, a ZIM Vetor Norte inclui como ZDEM de Grandes Equipamentos as áreas do aeroporto internacional Tancredo Neves, a área do Centro de Tecnologia e Capacitação Aeroespacial (CTCA) e o novo Centro de Instrução e Adaptação da Aeronáutica (CIAAR).

\section{Grandes Projetos Urbanos nos Vetores Norte e Sul}

A maior intensidade de GPUs na RMBH dialoga com literatura que descreve inflexões no padrão de acumulação que toma as grandes cidades como locais preferenciais de gerenciamento e de redução das crises do capital (Brenner, Peck, Theodore, 2012). A cidade torna-se, nesse contexto, locus preferencial no qual as transformações econômicas se materializaram com maior nitidez, estabelecendo "uma nova malha locacional para o processo de acumulação" (Brenner, Theodore, 2002, p. 355). Decorre dessa condição as cidades tornarem-se objeto central da implementação de reestruturações físico-territoriais, político-experimentais, inovações institucionais e projetos político-ideológicos de transposição e regulamentação das novas regras do mercado de capitais global sobre as políticas locais (Sánchez, 2010). Essa tendência prioriza práticas de intervenção de curto prazo sobre o tecido urbano, sobretudo aquelas voltadas para implementação de grandes projetos de reestruturação urbana (Altshuler, Luberoff, 2003).
A distribuição territorial dos grandes projetos urbanos previstos ou realizados entre 2000 e 2018 na RMBH está concentrada em dois vetores de expansão. No Vetor Norte, no qual ocorrem transformações intensas por meio da instalação de novos equipamentos públicos e empreendimentos privados e a requalificação da infraestrutura existente; e no Vetor Sul, no qual o projeto CSul propõe um novo distrito nos moldes da escola de novo urbanismo, articulando uma série de empreendimentos privados em torno de um masterplan de longo prazo. 0 modo como esses projetos se articulam ao PDDI-RMBH e o modo como foram incorporados ao Macrozoneamento Metropolitano como parte integrante de uma estrutura urbana existente, dada sua potencial viabilidade em curto prazo, levanta questões sobre o campo do planejamento, incluindo a vulnerabilidade das instâncias de participação diante da imposição de uma lista de intervenções definida por interesses e articulações privados; e o risco de captura do planejamento como estratégia de legitimação desses interesses, seja por meio de ampliação do capital cultural e político de seus empreendedores, seja pelas possibilidades de ganho fundiário e especulativo relacionado ao zoneamento e à desigual distribuição dos investimentos públicos (Freitas, 2017).

0 intenso processo de reestruturação econômica e socioespacial do Vetor Norte tem início com a reativação do aeroporto internacional Tancredo Neves ainda em 2004, seguida pela implantação da Cidade Administrativa de Minas Gerais (CAMG) no bairro Serra Verde (inaugurada em 2010 para concentrar os principais órgãos e secretarias do Governo do Estado, antes dispersos na área central); e pelos incentivos para criação de 
um polo de semicondutores e de microeletrônica (com poucos resultados concretos até o momento); além dos investimentos viários, como a Linha Verde (ligando Belo Horizonte ao aeroporto), a duplicação da MG-020 e da avenida Antônio Carlos/Pedro I e os investimentos no sistema de BRT ao longo dos corredores da Antônio Carlos e Cristiano Machado. Todas essas intervenções tiveram como fundamento a ideologia "modernizante" do governo estadual peessedebista que, entre 2003 e 2015, buscou inserir Belo Horizonte nos circuitos internacionais do capital através de incentivos às atividades culturais, à atração de grandes eventos e exposições e à implantação de indústrias densas em tecnologia e processos produtivos modernos. Os empreendimentos e planos voltados para o Vetor Norte buscaram, assim, incrementar as exportações da RMBH, atrair capitais externos, centralizar as estruturas da administração pública estadual e fornecer uma alternativa residencial para as classes médias e altas que ali passaram a trabalhar.

Alinhado a esse projeto, em dezembro de 2008, o Governo do Estado contratou a consultoria Jurong Internacional, de Cingapura, para preparar um plano estratégico para a RM$\mathrm{BH}$, orientado pelo conceito da Aerotrópole, tal como idealizado pelo consultor norte-americano John Kasarda, que resultou no Plano Macroestrutural do Vetor Norte de 2010. Em dezembro de 2012, o governo contratou a empresa $\mathrm{CH} 2 \mathrm{M}$ Hill do Brasil Engenharia Ltda, para preparar o novo masterplan econômico da $\mathrm{RMBH}$. A lógica que pautou esse último plano pouco difere do anterior, evoluindo no detaIhamento de áreas-alvo e no macrozoneamento do território do Vetor Norte e das alças Oeste e Sul do projeto do Rodoanel. É importante notar que, durante esse período era também elaborado o PDDI-RMBH pela UFMG, contratada pela Sedru, enquanto esses outros planos eram contratados pela Secretaria de Desenvolvimento Econômico (Sede), o que revela de partida uma clivagem dentro do próprio governo do estadual que expressa um potencial conflito entre o planejamento territorial compreensivo e participativo em oposição ao planejamento territorial estritamente econômico, tomado como estratégico pelo estado.

Um dos produtos desse conjunto de planos com ênfase no planejamento econômico foi o esforço de identificação de projetos pontuais públicos e privados em curso que passam a ser articulados ao AITN para, em seguida, ampliar o potencial econômico do conjunto e sua atratividade a investidores privados. Um exemplo desse tipo de produto é o mapa "Uso do solo - Projetos planejados por outros", apresentado no estudo elaborado pela consultoria CH2M Hill em abril de 2013 (Figura 3). O mapeamento apresenta uma ampla lista de 72 projetos localizados no Vetor Norte e 7 projetos privados localizados nas demais regiões da $\mathrm{RMBH}$. O conjunto de agentes envolvidos nesses projetos inclui proprietários de terrenos de grande porte, indústrias de diferentes segmentos, condomínios residenciais e empresas interessadas em se instalar na região. No contexto em que é apresentado - de legitimação de um plano de macrozoneamento estratégico que depende de adesão de investidores privados -, o mapa cumpre a função de demonstrar que os investimentos em infraestrutura despertaram o interesse do setor privado na região e inauguraram novas frentes de interesse do mercado imobiliário. No entanto, o que a lista de projetos apresenta, de fato, são potenciais parceiros, a maior parte sem estudo de viabilidade ou mesmo sem intenção de investimento 
Figura 3 - Mapa apresentado no masterplan econômico da RMBH

("Uso do solo - Projetos planejados por outros")

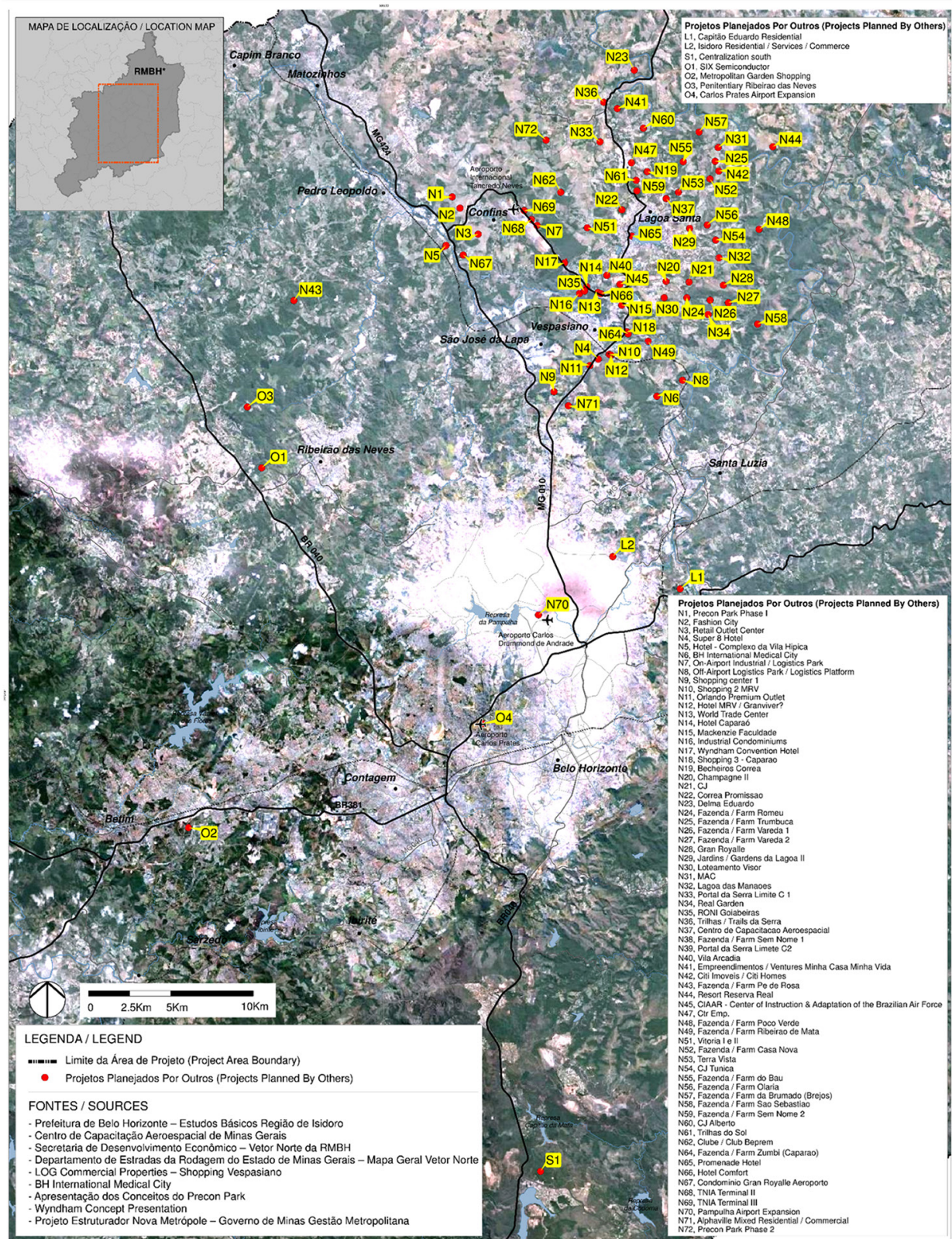

Master Plan Econômico da RMBH / BHMR Economic Master Plan

Fonte: CH2M Hill (2013). 
em curto prazo, com alto potencial de beneficiar-se dos investimentos públicos, mas sem interesse ou condições de promover o desenvolvimento esperado.

Concomitante à elaboração dos estudos acima, o Governo do Estado e a Prefeitura de Belo Horizonte promoveram uma série de investimentos em infraestrutura no Vetor Norte. Ainda que o Rodoanel Metropolitano, principal obra estruturante de grande influência sobre o plano de centralidades e expansão metropolitana, não tenha se viabilizado, a conclusão da Linha Verde e a instalação da Cidade Administrativa, bem como o anúncio de uma série de novos investimentos públicos e privados na região, apontam para uma tendência de reestruturação territorial orientada pelo interesse imobiliário que corre o risco de gerar um tecido urbano fragmentado e espraiado de forma não planejada ao longo dos novos eixos viários e no entorno dos grandes equipamentos públicos.

Entre os empreendimentos privados, os três principais projetos, o Precon Park/ Terras do Fidalgo, o megaempreendimento residencial de alta renda Reserva Real e a nova centralidade localizada em propriedade da empresa Aterpa, não corresponderam às expectativas iniciais. O Precon Park, cujo plano mestre passou por inúmeras revisões, abrange um conjunto de três terrenos de grande porte da empresa (originalmente do setor cimenteiro e construção civil). 0 empreendimento privado tenta articular um conjunto de empreendimentos e investidores parceiros de diferentes segmentos localizados dentro ou no entorno imediato desses terrenos, entre eles, o shopping Fashion City, que tinha previsão de conclusão em 2016, mas ainda não foi inaugurado; a previsão de um novo empreendimento do grupo Alphaville, semelhante ao Alphaville Vespasiano recém-inaugurado no entorno imediato; a revitalização de parte da Faculdade de Pedro Leopoldo, parcialmente concluída; e o campo de futebol Arena da Bola, já operando. A construção do condomínio Reserva Real, iniciativa do grupo português Design Resorts articulado a investidores nacionais e internacionais, foi interrompida em 2015, após escândalo relacionado à venda de lotes sem infraestrutura, situação agravada pelo anúncio do Governo do Estado, em 2016, de que não realizaria a construção da nova rodovia que conecta o local ao AITN.

Além dos projetos acima, o masterplan econômico da RMBH elaborado pela empresa $\mathrm{CH} 2 \mathrm{M}$ Hill previa três novas centralidades, uma delas articuladas com a centralidade prevista anteriormente em propriedade da empresa Aterpa e projetada pela empresa de consultoria Aecom, conforme indicação original do PDDI. As novas centralidades, embora aparecessem com destaque no estudo Aerotrópole de Belo Horizonte de 2013 contratado pela Sede (Figura 5), não se viabilizaram. Mais próximo de Lagoa Santa, vinculado à tradição relacionada à atividade aeronáutica na cidade, está prevista a construção do Centro de Treinamento e Controle da Aeronáutica (CTCA), aguardando manifestação de interesse do setor privado, e já foi concluído o Centro de Instrução e Adaptação da Aeronáutica (CIAAR).

Três fatores foram determinantes na localização dos GPUs acima: o ganho locacional proporcionado pelo conjunto de investimentos públicos; o cenário político-institucional favorável a novos investidores; e a estrutura fundiária caracterizada pelas grandes propriedades de terra ao redor do aeroporto. Cabe registrar, ainda, o aumento de lançamentos 
Figura 4 - Mapa dos grandes projetos urbanos da RMBH

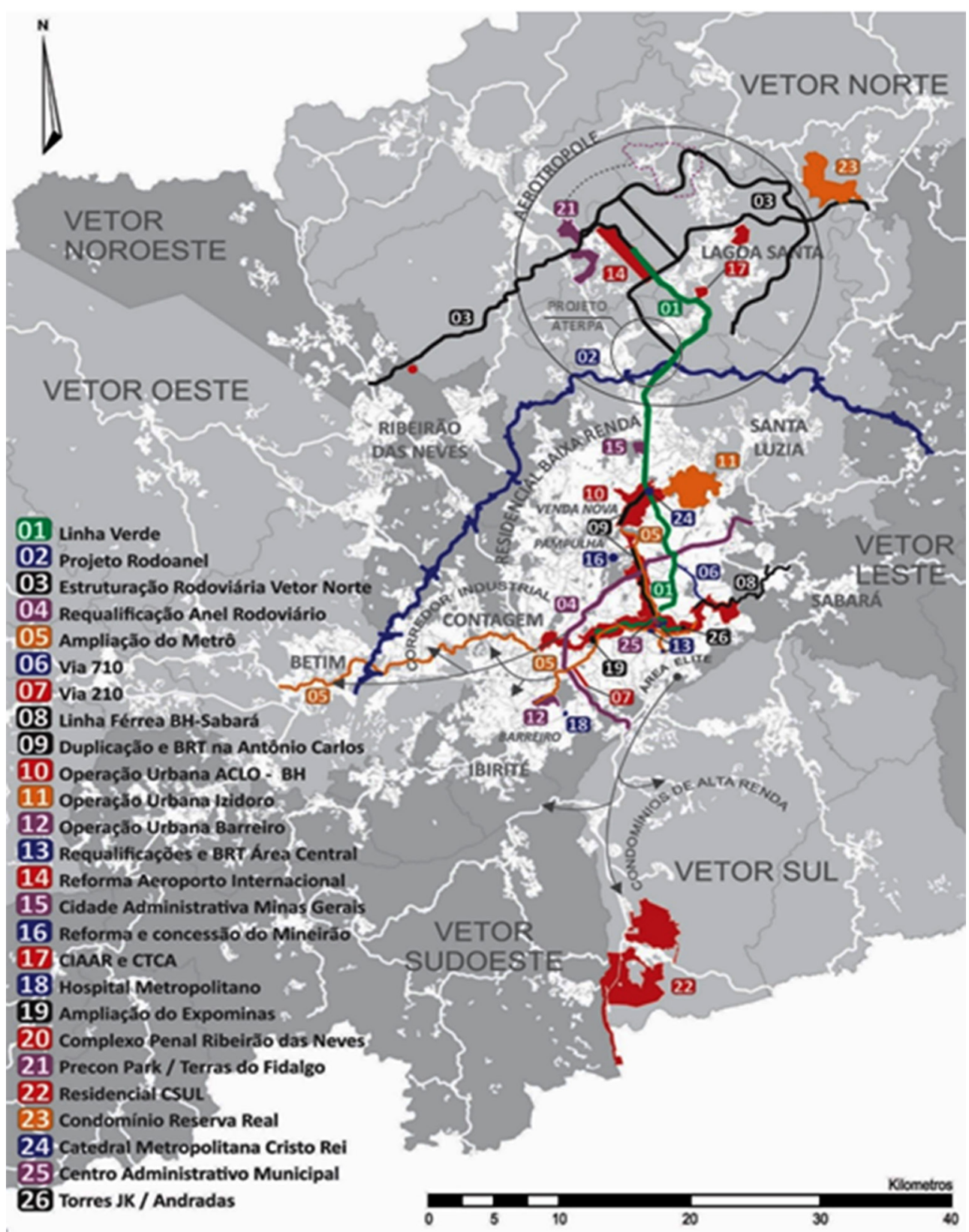

Fonte: Freitas (2017). 
Figura 5 - Centralidades propostas no masterplan econômico
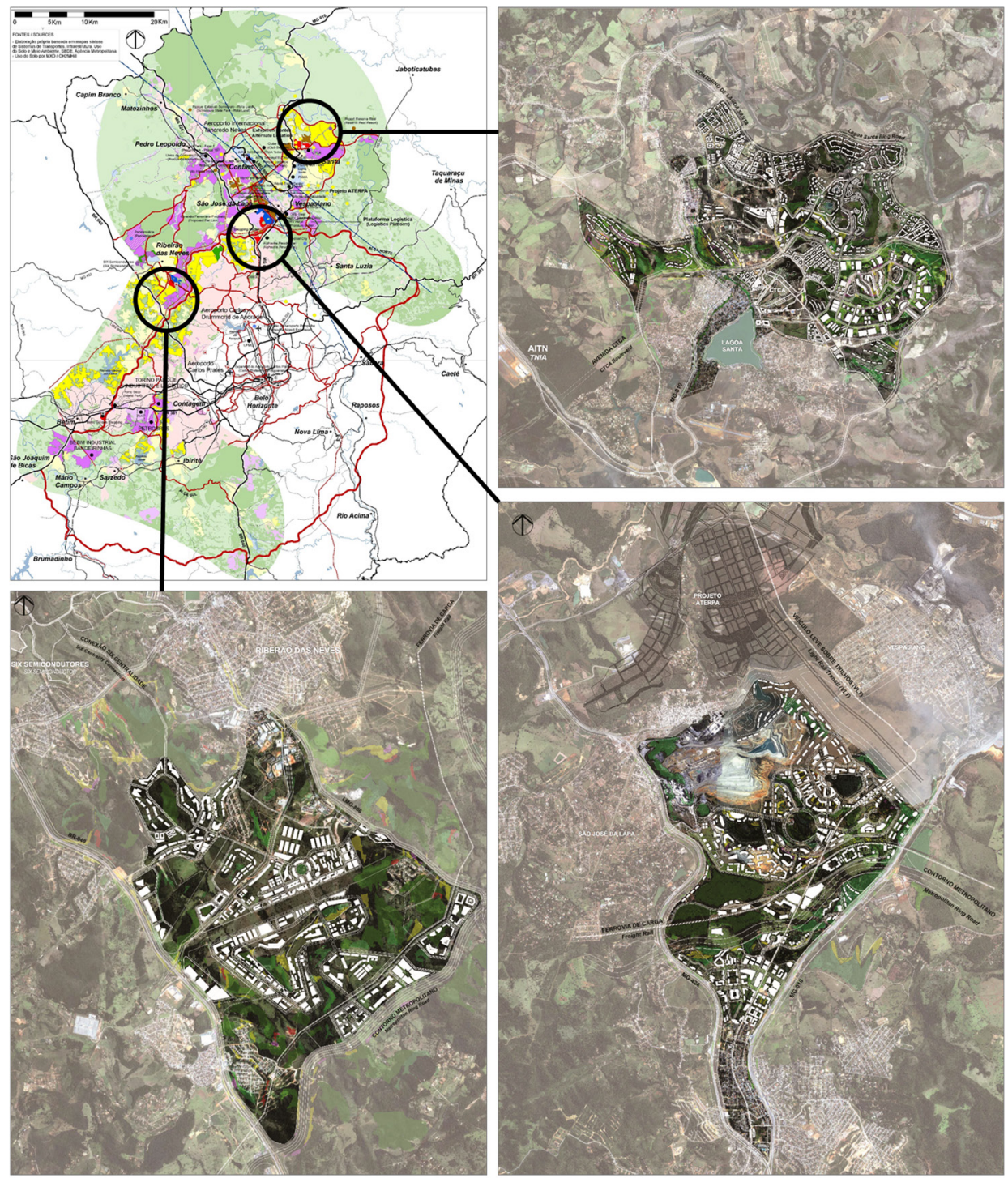

Fonte: $\mathrm{CH} 2 \mathrm{M}$ Hill (2013). 
imobiliários de menor porte do tipo condomínio residencial observado na região. Em um cenário no qual os empreendimentos acima fossem concluídos, e mantida a tendência de lançamento residencial observada, teríamos uma potencial desarticulação do território através de grandes enclaves privados, combinada à pressão por novos loteamentos e por legislações municipais mais permissivas, podendo levar a avanços sobre as áreas de proteção ambiental, substituição de população, agravamento da exclusão socioespacial e novos ciclos de periferização (Freitas, 2017).

O cenário contradiz a proposta de centralidade apresentada no PDDI-RMBH no que diz respeito à oferta de moradia a segmentos de baixa renda, incluindo Habitação de Interesse Social; à promoção de um sistema viário em rede, uma vez que reforça o papel radial dos corredores Antônio Carlos e Cristiano Machado; e à promoção de uma vida urbana articulada à cultura e ao meio ambiente, uma vez que reforça a tipologia condomínio, shopping center e equipamentos monofuncionais, além de pressionar o crescimento urbano sobre áreas de interesse ambiental e de patrimônio arqueológico da região.

Já o Vetor Sul de expansão metropolitana (que segue a BR-040 no sentido Rio de Janeiro e a MG-030 no sentido de Nova Lima) constitui uma região de grande beleza cênica e paisagística, detentora de um importante patrimônio ambiental e de recursos naturais estratégicos (como o minério de ferro e os principais mananciais de água da RMBH). Durante a década de 1980, foi instituída a APA-Sul (Área de Proteção Ambiental da Região Sul da RMBH), sendo a maior parte de suas terras de propriedade de mineradoras, grandes latifundiárias da região. Desde a década de 1990, a expansão dos condomínios e loteamentos fechados da elite ao longo do eixo Sul tem redefinido a dinâmica regional e urbana desse território, ampliando os conflitos pelo uso do espaço em torno do tripé recursos hídricos $\mathrm{x}$ mineração $\mathrm{x}$ ocupação de alta renda (Costa, 2003).

Mais recentemente, a previsão de uma nova polarização terciária ao longo da BR040, em função da demanda dos grupos de alta renda localizados nos parcelamentos residenciais fechados da região, acompanhada do sobrecarregamento do corredor viário e escassez de espaços e equipamentos públicos (UFMG, 2011), vem se confirmando por meio do aumento no volume de lançamentos imobiliários, bem como pela instalação de outros usos (sede de empresas, edifícios culturais, faculdades, hospitais, serviços avançados, entre outros). Caracterizam os novos projetos na região: a) a manutenção do investimento em grandes parcelamentos fechados (os "condomínios"), historicamente marcados pela parceria entre os proprietários de terras, geralmente mineradoras, e grupos investidores de maior porte; b) investimentos na ampliação da mineração, sobretudo em atividades logísticas; e c) novos usos ligados ao desenvolvimento da centralidade sul.

Diferentemente do Vetor Norte, no qual o Estado precisou criar amenidades para potenciais investidores, no Vetor Sul existe um histórico de legislação que induziu o tipo de parcelamento voltado para classes altas e que, quando necessário, tal legislação é flexibilizada para permitir a ocupação de áreas de maior fragilidade ambiental (Costa et al., 2006). Mais próximo de Belo Horizonte, a verticalização do bairro Vila da Serra e do Vale do Sereno foi intensificada na última década, motivada pelo aquecimento do mercado 
imobiliário de luxo. A articulação entre proprietários de terra e investidores confirma-se no Vale dos Cristais, lançado pela Odebrecht em terreno de 6.500 hectares da mineradora Anglo Gold, e o projeto do Condomínio Águas Claras da Vale, em terreno onde se pretende recuperar a extinta mina.

Em 2009, o estudo "Programa de Ações Estratégicas do Vetor Sul da Região Metropolitana de Belo Horizonte", elaborado pelo Instituto Horizontes e patrocinado pela Associação dos Empreendedores da Vila da Serra e Vale do Sereno e pelas empresas Anglogold, Vale e BH Shopping, reconheceu as pressões sobre a região e propôs um planejamento de longo prazo capaz de equacionar o "confronto entre as vocações e potencialidades da área" (Instituto Horizontes, 2009, p. 2) caracterizada por novos empreendimentos e atividades estimulados pelo aumento da população de renda média e alta e dos empreendimentos cada vez mais complexos, associando verticalização com parcelamentos horizontais - com destaque para a ampliação do Alphaville -, e pelo crescimento econômico e demográfico esperado para a região do Alto Paraopeba, mais ao sul na BR-040 (UFMG, 2011, p. 216). Incorporado parcialmente pelo PDDI, o programa, embora dê maior ênfase ao transbordamento de Belo Horizonte em direção a Nova Lima, discutiu também as potenciais centralidades no bairro Jardim Canadá e no entorno do condomínio Alphaville Lagoa dos Ingleses, inaugurado na década 1990 em área de "localização estratégica, no cruzamento da BR-040 com a BR-356, numa região de topografia favorável à ocupação urbana e a uma distância razoável do centro a metrópole" (Instituto Horizontes, 2009, p. 11).

A expansão urbana incentivada pela prefeitura de Nova Lima desde o Plano Diretor de
2007, mais especificamente a ocupação residencial, comercial e de serviços no entorno do Alphaville, ganha contornos mais nítidos quando é anunciado o empreendimento CSul, que representa um aumento na escala dos empreendimentos privados existentes no local e propõe sua compatibilização com grandes equipamentos, resultando em nova estratégia de atração de investidores. 0 masterplan do empreendimento, elaborado pelo consultor Jaime Lerner, propõe a constituição de uma centralidade metropolitana em terreno de cerca de 2 mil hectares. 0 principal esforço do plano mestre consiste em articular um grupo de empreendimentos pontuais de diferentes segmentos, incluindo usos empresariais, tecnológicos, de logística e, sobretudo, residenciais, com previsão de assentar, nos próximos 50, anos cerca de 109 mil moradores no local. Tal como no Vetor Norte, o planejamento estratégico do Vetor Sul foi elaborado em paralelo ao PDDI e, também, realizou esforço de integração ao plano metropolitano:

Foi a partir do PDDI que o grupo de investidores responsáveis pela criação da CSul - Desenvolvimento Urbano identificou a possibilidade de desenvolver projetos multisetoriais no eixo Sul da RMBH. Nessa região, o PDDI prevê a implantação de uma série de ações e projetos de fomento, com o objetivo de fortalecer uma nova centralidade a Centralidade Sul, de forma a induzir o desenvolvimento planejado e sustentável do Vetor Sul da RMBH. ${ }^{6}$

0 grupo da CSul que adquiriu o terreno em outubro de 2013 é uma holding formada por empresas que têm como meta a atração de 20 bilhões de reais em investimento na região ao longo de 30 anos. 0 grupo é formado pelas 
empresas BVEP-Votorantim, AGHC, Barbosa Mello, Asamar e Alicerce Empreendimentos e inclui no escopo do projeto outros investimentos realizados ou programados: do grupo Iguatemi, que investiu 140 milhões em shopping Premium Outlet, atualmente em construção e previsto para ser inaugurado em 2019; da EPO Engenharia, que investiu 60 milhões no empreendimento Navegantes, previsto para 2019; da Coca Cola Femsa, que investiu 900 milhões em fábrica própria concluída em 2017; da empresa Biomm, que investiu 540 milhões em fábrica própria, concluída em 2018; da empresa Suplimed, que investiu 15 milhões em fábrica de equipamentos oftalmológicos, em construção; do Grupo Costa Laguna, que investiu 120 milhões em condomínio concluído em 2017; da RKM Engenharia, que investiu 85 milhões no Lótus Condomínio Resort, em construção; do grupo paulista Rezek, que investiu $\mathrm{R} \$ 200$ milhões no Condomínio Vila Parque Lagoa dos Ingleses, também em construção.

Também de modo semelhante ao que ocorre no Vetor Norte, o MZ-RMBH reconheceu e incorporou essa nova centralidade a ser implantada, dotando o empreendimento de maior capital político, na medida em que inaugurou uma potencial parceria entre o interesse do poder público e a proposta dos investidores. Essa articulação foi legitimada em 18 de agosto de 2015, no momento em que o governo de Minas, já sob o governo do PT, assinou um comunicado oficial de apoio ao projeto, com o intuito, segundo Waldir Salvador, superintendente da CSUL, de: "[...] viabilizar ações de infraestrutura e de fomento econômico e social, por meio de parcerias com o Instituto de Desenvolvimento Integrado de Minas Gerais (Indi), o Banco de Desenvolvimento do Estado de Minas Gerais (BDMG) e a Companhia de Gás de Minas Gerais (Gasmig)". Assim, e a despeito da crise econômica, a CSul vem sendo implementada com apoio do Estado, tendo conseguido, em setembro de 2018, a licença prévia pelo Conselho Estadual de Política Ambiental (Copam), sob o forte protesto de movimentos ambientalistas da região que questionam principalmente a viabilidade do projeto quanto à disponibilidade hídrica futura. ${ }^{7}$

\section{Conclusões preliminares}

Como se pode depreender dessa breve trajetória do planejamento metropolitano e dos grandes projetos urbanos no Vetor Norte e Vetor Sul da RMBH, nesta última década principalmente, os interesses privados e os projetos estratégicos do Governo do Estado parecem se sobrepor aos objetivos e às políticas de longo prazo estabelecidas no âmbito do Plano Metropolitano e de seus desdobramentos posteriores. Não se pode, no entanto, afirmar que os grandes projetos urbanos, sejam públicos ou privados, se fazem exatamente à revelia do planejamento metropolitano, na medida em que seus projetos já haviam sido parcialmente incorporados na própria elaboração do PDDI e do MZ-RMBH, além disso muitos deles se apropriaram seletivamente de políticas e programas do Plano Metropolitano para embasar e justificar determinadas opções. O caso das centralidades metropolitanas Norte e Sul revela de modo mais claro as sobreposições e sombreamentos entre o planejamento metropolitano e a agenda dos grandes projetos urbanos, ao mesmo tempo que explicita um crescente descolamento entre as diretrizes das propostas do PDDI e o 
formato assumido pelos projetos privados para novas centralidades.

Ainda em 2012, Magalhães et al. chamavam a atenção para alguns riscos de uma eventual implementação incompleta da política de centralidades do PDDI: caso essas centralidades se tornassem de fato localização privilegiada para residência de camadas população de renda mais elevada e/ou para empresas de setores mais avançados, a valorização imobiliária resultante colocaria maiores barreiras à presença de grupos de renda mais baixa e/ou de atividades econômicas mais populares, podendo até gerar uma pressão pela expulsão dessas camadas. Os autores defenderam que o provimento de habitação de interesse social inserido nas áreas internas às centralidades seria um elemento fundamental para que a política de centralidades não aumentasse as probabilidades de engendrar processos de gentrificação e expulsão da população de renda mais baixa, e para que existisse uma possibilidade garantida de que esses grupos se apropriassem de fato do espaço urbano nas novas centralidades, que deveriam fazer prevalecer a diversidade social e cultural do espaço urbano em detrimento de enclaves de alta renda.

À época da elaboração do PDDI, já se manifestavam visões contrárias quanto à política de centralidades metropolitanas: alguns defendiam a necessidade de fortalecer as centralidades existentes, internas à mancha urbana consolidada, e colocar maiores restrições à expansão metropolitana; outros, acreditando que o processo de urbanização dispersa seria de certo modo inevitável, defendiam a criação de novas centralidades para melhor aproveitar projetos e processos de crescimento já em curso, buscando dar-Ihes maior coesão e densidade por meio da sua concentração seletiva em alguns espaços. A segunda opção parece ter sido a adotada, o que confirmaria a hipótese de uma permeabilidade do planejamento metropolitano à atuação do Estado e do capital, relevada na própria natureza metodológica da elaboração do PDDI-RMBH e do MZ-RMBH, que procuraram mais incorporar e articular interesses divergentes do que se contrapor de maneira mais conflitiva com agendas não necessariamente convergentes.

O caso da Centralidade Sul aparecia como o mais controverso, pois envolve uma área detentora de importantes recursos ambientais já sobrecarregados, uma subcentralidade mais diversificada em formação na região do Jardim Canadá, além de claros movimentos de grandes investimentos privados no entorno do Alphaville. Esses investimentos vieram a se consolidar como o projeto CSul, em estreita negociação com a prefeitura de Nova Lima, e que, como visto, se encontra já em fase de implantação com apoio do Governo do Estado.

Quanto ao Vetor Norte, havia um entendimento mais estabelecido, por conta de todos os investimentos públicos e privados previstos e em curso, além da instalação do próprio centro do poder estadual, de que seria necessário estabelecer alguma forma de centralidade que congregasse e atendesse a essa diversidade de demandas. Não obstante, o projeto previsto pela Aecom para a Centralidade Norte não se viabilizou, por motivos ainda não claramente esclarecidos pelos autores. Além da própria crise econômica, é possível supor que a não viabilização do Rodoanel - que conectaria a nova centralidade a outras porções da RMBH tenha contribuído para o abandono do projeto, a que se seguiram vários outros grandes projetos abandonados, reformulados ou diminuídos no Vetor Norte. 
Essas visões se cristalizaram na proposta regulatória do macrozoneamento, que incorporou, na delimitação das ZIMs do Vetor Norte e Sul, a territorialização dos próprios GPUs subjacentes. Não obstante essa incorporação - levada mais adiante na etapa de negociação do projeto do MZ-RMBH da Agência RMBH com prefeitos e parceiros privados, não se pode falar também de uma convergência total. Um dos aspectos em que se evidenciam mais claramente as controvérsias entre a proposta da centralidade do PDDI - como espaços densos, públicos e socialmente diversos - e os projetos privados - caracterizados pela presença de loteamentos fechados, urbanização dispersa e atração de setores de ponta - foi quanto à presença de habitação de interesse social (HIS) nas centralidades.

$\mathrm{O}$ projeto original do MZ-RMBH, elaborado pela UFMG, propunha que $20 \%$ das novas unidades habitacionais fossem destinadas à HIS, para famílias com rendimentos entre 0 e 3 salários mínimos. Já, no projeto de lei enviado à Assembleia Legislativa (PL 74/2017), define-se que, nas Zonas de Adensamento e Diversificação (ZDAs), que correspondem às centralidades, $10 \%$ da área líquida de lotes deve servir para atendimento a famílias com renda de 0 a 3 salários mínimos, para parcelamentos com mais de $40.000 \mathrm{~m}^{2}$. Essa alteração foi resultante da pressão do empresários do setor imobiliário no âmbito do Conselho Metropolitano, em conflito com outras entidades da sociedade civil que defendiam maior percentual. De qualquer modo, como o projeto de lei 74/2017 ainda não foi aprovado, não é claro se o empreendimento CSul precisará cumprir tais exigências. De modo geral, pode-se dizer que o projeto CSul se aproveitou dos bônus do planejamento metropolitano, tendo até então conseguido se desvencilhar dos seus ônus relativos à responsabilidade territorial.

Há que se ressaltar ainda que, enquanto as propostas do PDDI e do MZ-RMBH foram construídas com participação da comunidade metropolitana, tendo sido referendadas publicamente em seminários e eventos participativos ao longo de todo o processo, além de aprovadas pelo Conselho Metropolitano, alterações posteriores nos dois projetos parecem ter sido feitas em negociações diretas entre a Agência RMBH e grupos privados de proprietários/incorporadores, para além do espaço de negociação de ajustes do macrozoneamento com as prefeituras municipais levado a cabo pelo estado. As alterações principais são evidentes nos limites e divisões internas dos zoneamentos das centralidades Norte e Sul, entre a proposta original e a enviada à Assembleia, o que nos leva a indagar sobre a legitimidade democrática de decisões quanto ao planejamento metropolitano que se dão sem a devida participação popular e transparência exigidas pela legislação.

Cabe apontar, ainda, um conjunto de questões e hipóteses que continuam em aberto, convidando para a continuidade da investigação em diálogo com debates mais amplos no âmbito dos estudos urbanos. Inicialmente, seria importante aprofundar uma leitura da articulação política entre Estado, mercado e sociedade a partir do debate conceitual e das aplicações em pesquisa da Teoria dos Regimes Urbanos, sobretudo a problematização da relação entre as novas coalizões de poder e o contexto de uma inflexão ultraliberal no Brasil caracterizada principalmente pelo empresariamento da política urbana (aqui, em nível metropolitano) e por uma nova regulação orientada pelos interesses de mercado. 
Ademais, as novas tipologias de intervenção urbana, as novas modalidades e intensificação das parcerias com o capital privado e a abertura de capital das grandes empresas atuantes no campo são alguns dos sinais de um contexto que parece favorável ao processo de neoliberalização urbana colocada em discussão. Ainda, caberia aprofundar as investigações para aferir o quanto desses processos pode ser explicado pela hipótese de financeirização da política urbana e dos mercados fundiários e imobiliários, geralmente discutido em nível nacional, considerando-se as especificidades da RMBH.

Quanto ao planejamento metropolitano, cabe indagar se podemos falar de um processo de empresariamento da gestão metropolitana, processo que, se confirmado, ocorre atravessado por contradições e influenciado por múltiplos atores, inclusive pela participação da UFMG e de alguns setores mais organizados da sociedade civil. Ademais, o caso das novas centralidades metropolitanas explicita um descompasso entre a racionalidade dos grandes projetos urbanos, fragmentada e de curto prazo, ou mesmo estratégica, e a racionalidade concebida para um planejamento metropolitano compreensivo e de longo prazo, tal qual preconizado no PDDI, no qual caberia maior papel coordenador e mesmo interventor por parte do Estado. Outro conflito identificado foi entre as instâncias de gestão e planejamento metropolitanos e as políticas setoriais e estratégicas do Governo do Estado, principalmente aquelas levadas a cabo pela Secretaria de Desenvolvimento Econômica (Sede) para o Vetor Norte, que potencializou a concepção e a execução de alguns GPUs.

Por fim, ressaltamos que, mais do que tomar a gestão metropolitana como processo autônomo, trata-se de reconhecê-la como esfera de conflito, negociação e legitimação em que comparecem agendas contraditórias que carregam projetos distintos, mas em que os capitais investidos na produção do espaço, principalmente por meio dos grandes projetos urbanos com apoio do Estado, parecem ser mais decisivos do que a força do Plano Metropolitano no desenho futuro da estrutura territorial da RMBH.

\section{[I] https://orcid.org/0000-0002-4298-455X}

Universidade Federal de Minas Gerais, Faculdade de Ciências Econômicas, Centro de Desenvolvimento e Planejamento Regional. Belo Horizonte, MG/Brasil.

joaotonucci@cedeplar.ufmg.br

\section{[II] https://orcid.org/0000-0002-3056-3029}

Universidade Federal de Minas Gerais, Escola de Arquitetura e Design, Departamento de Urbanismo. Belo Horizonte, MG/Brasil.

danielmedeirosdefreitas@gmail.com 


\section{Notas}

(1) Versão preliminar deste trabalho foi apresentada no XVIII Enanpur (realizado em Natal, em 2019). Agradecemos aos participantes da sessão temática pelo debate e comentários, assim como aos pareceristas anônimos que avaliaram a versão final deste artigo pelas sugestões e recomendações.

(2) O conceito adotado para Grandes Projetos Urbanos (GPUs) considera que esse tipo de projeto se apresenta como ruptura na produção do tecido urbano, concebido como formas fechadas, em escala superior à tradicionalmente praticada no local, gerando, através de hegemonia do projeto em detrimento do plano de longo prazo, objetos icônicos que abrigam atividades restritas e homogêneas. Esses objetos são determinados por heranças históricas, agravadas por recentes inflexões na economia global e pelo alinhamento entre Estado e capital, em contexto permeado por paradigmas hegemônicos de produção da forma urbana (Freitas, 2017).

(3) Sobre a trajetória do planejamento metropolitano da RMBH anterior, ver Tonucci Filho (2012).

(4) O PDDI-RMBH foi contratado em 2009 pela Secretaria de Estado de Desenvolvimento Regional e Política Urbana (Sedru/MG) ao Centro de Desenvolvimento e Planejamento Regional da Universidade Federal de Minas Gerais (Cedeplar/Face/UFMG), através da Fundação Instituto de Pesquisas Econômicas, Administrativas e Contábeis de Minas Gerais (Ipead). A versão final do Plano foi entregue para apreciação do Governo do Estado em maio de 2011 e, em julho de 2011, após sessão no Conselho Deliberativo de Desenvolvimento Metropolitano, o PDDI foi aprovado por aclamação. O Plano foi elaborado por uma equipe que contou com a participação direta de professores e alunos de pós-graduação e graduação de várias unidades da UFMG, além da Pontifícia Universidade Católica de Minas Gerais (PucMinas) e da Escola de Design da Universidade Estadual de Minas Gerais (UEMG). O documento final consolidado do PDDI, em seis volumes, compõe-se da Proposta de Reestruturação Territorial Metropolitana, da Proposta Institucional para implementação do Plano, e de vinte e oito Políticas Metropolitanas. Para mais informações, ver o portal: www.rmbh.org.br.

(5) Mais informações em: http://www.agenciarmbh.mg.gov.br/macrozoneamento/.

(6) http://www.csullagoadosingleses.com.br/. Acesso em: nov 2018.

(7) https://www.em.com.br/app/noticia/gerais/2018/09/25/interna_gerais,991702/conselho-aprovalicenca-previa-para-megaempreendimento-na-serra-da-moe.shtml. Acesso em: nov 2018.

\section{Referências}

ALTSHULER, A.; LUBEROFF, D. (2003). Mega-projects. The changing politics of urban public investment. Washington, Booking Institution Press.

BRENNER, N.; PECK, J.; THEODORE, N. (2012). Após a neoliberalização? Cadernos Metrópole. São Paulo, v. 14, n. 27, pp. 15-39.

BRENNER, N.; THEODORE, N. (2002). Cities and the geographies of "actually existing neoliberalism". Antipode, v. 34, n. 3, pp. 349-379. 
CH2M HILL (2013). Fase 1 e 2. Análise de Mercado e Condições existentes do local/transporte e alternativas prévias dos planos rodoviários. Relatório Técnico. CH2M HILL/SEDE.

COSTA, H. S. de M. (2003). “Natureza, mercado e cultura: caminhos da expansão metropolitana de Belo Horizonte". In: MENDONÇA, J. G. de; GODINHO, M. H. (orgs.). População, espaço e gestão na metrópole: novas configurações, velhas desigualdades. Belo Horizonte, PUC Minas.

COSTA, H. S. de M.; COSTA, G. M.; MENDONÇA, J. G.; MONTE-MÓR, R. L. de M. (2006). Novas periferias metropolitanas: a expansão metropolitana em Belo Horizonte: dinâmica e especificidades no Eixo Sul. Belo Horizonte, c/Arte.

FREITAS, D. M. de (2017). Campo de poder dos grandes projetos urbanos da Região Metropolitana de Belo Horizonte. São Paulo, Annablume.

INSTITUTO HORIZONTES (2009). Programa de Ações Estratégicas do Vetor Sul da Região Metropolitana de Belo Horizonte. Relatório Técnico. Belo Horizonte.

MAGALHÃES, F. N. C.; TONUCCI FILHO, J. B. M.; ARAÚJO, R. P. Z.; COSTA, H. S. de M. (2012). Em busca de rearranjos metropolitanos: uma discussão crítica da proposta de restruturação territorial do Plano Diretor de Desenvolvimento Integrado da RMBH. In: XV SEMINÁRIO SOBRE A ECONOMIA MINEIRA. Anais.... Diamantina.

SÁNCHEZ, F. (2010). A reinvenção das cidades para um mercado mundial. Chapecó, Argos.

SEDRU (2009). Termo de Referência para contratação de Serviços Técnicos Especializados para elaboração do Plano Diretor de Desenvolvimento Integrado - PDDI da Região Metropolitana de Belo Horizonte - RMBH. Belo Horizonte.

TONUCCI FILHO, J. B. M. (2012). Dois momentos do planejamento metropolitano em Belo Horizonte: um estudo das experiências do Plambel e do PDDI-RMBH. Dissertação de Mestrado. São Paulo, Universidade de São Paulo.

TONUCCI FILHO, J. B. M.; MONTE MÓR, R. L. M. (2013). Avanços e desafios ao planejamento metropolitano: o caso do PDDI-RMBH. In: XV ENANPUR. Anais... Recife.

UFMG (2011). Plano Diretor de Desenvolvimento Integrado da Região Metropolitana de Belo Horizonte - PDDI-RMBH. Produto 6 - Relatório Final - Definição das Propostas de Políticas Setoriais, Projetos e Investimentos Prioritários. Belo Horizonte, UFMG.

(2015). Macrozonemento da RMBH. Produto 5. Definição dos Parâmetros Urbanísticos e de Diretrizes Específicas de Estruturação e Desenvolvimento para as Zonas de Interesse Metropolitano (ZIMs). Belo Horizonte, UFMG.

Texto recebido em 16/jun/2019

Texto aprovado em 12/ago/2019 